\title{
Üst gastrointestinal sistem endoskopisi: 7703 olgunun retrospektif analizi
}

\author{
Upper gastrointestinal endoscopy: A retrospective analysis of 7703 cases
}

Yusuf YÜCEL ${ }^{1,2}$, Alpay AKTÜMEN ${ }^{3}$, Timuçin AYDOĞAN ${ }^{4}$, Ahmet UYANIKOĞLU $^{4}$, Ahmet ŞEKER ${ }^{1}$, Orhan GÖZENELI ${ }^{1}$, Abdullah OZZGÖNÜL ${ }^{1}$, Alpaslan TERZI ${ }^{1}$, Ali UZUNKÖY ${ }^{1}$

Harran Üniversitesi Tip Fakültesi, ${ }^{1}$ Genel Cerrahi Anabilim Dall, ${ }^{4}$ Gastroenteroloji Anabilim Dah, Sanlurfa,

Karabük Üniversitesi Tip Fakültesi Eğitim ve Araştırma Hastanesi, ${ }^{2}$ Genel Cerrahi Anabilim Dall, ${ }^{3}$ Patoloji Anabilim Dall, Karabük

Giriş ve Amaç: Endoskopi ünitemizde üst gastrointestinal endoskopi uygulanan hastalarda özofagus, mide, proksimal duodenum hastalıkları sıklığının retrospektif olarak araştırılması amaçlanmıştır. Gereç ve Yöntem: Karabük Üniversitesi Eğitim ve Araștırma Hastanesi endoskopi ünitesinde 2006-2012 yılları arasında üst gastrointestinal sistem endoskopi yapılarak video arşivleme sistemine kaydedilen hastaların yaşı, cinsiyeti ve endoskopi raporlarındaki özofagus, mide ve proksimal duodenum hastalıklarn belirlendi. Bulgular: Üst gastrointestinal sistem şikayetleri nedeniyle 7703 hastaya endoskopik işlem yapıldı. Hastaların 4578'i $(\% 59,4)$ kadın, 3125’i $(\% 40,6)$ erkekti. Kadınların yaş aralığı 18-83 (ortalama: 57.8), erkeklerin 20-93 (ortalama: 54.3) yaş idi. Hastalarnn 565 'inin endoskopisinde patoloji tespit edilmedi. Olguların \%99.2'sinde üst gastrointestinal sistem endoskopisi topikal farenks aneztezisi ile yapıldı. Ust gastrointestinal sistem endoskopisi uygulanan olgularda mide kanseri oranı \%1.4 bulundu. Yapılan endoskopik işlemler sırasında komplikasyon ve mortalite oranı \%0 idi. Sonuç: Özofagogastroduodenoskopi, üst gastrointestinal sistem hastalıkların teşhisinde hala altın standarttır topikal farenks aneztezisi ile kolaylikla uygulanabilir, mortalite ve komplikasyon oranı oldukça düşük, tanısal bir işlemdir.

Anahtar kelimeler: Endoskopi, gastrointestinal sistem, mide kanseri

\section{GİRIS}

Üst gastrointestinal sistem (GIS) endoskopisi, özofagus, mide ve proksimal duodenum hastalıklarının tanısında yaygın olarak kullanılan, en güvenilir tanı yöntemidir. Bu yöntemin avantajı endoskopi yapılan organın iç yüzeyini direkt olarak görmek, lezyonlardan patolojik örnekleme yapabilmek, gerektiğinde de endoskopik tedavi uygulayabilmektir. Disfaji, retrosternal yanma/ağrı, epigastrik yanma/ağrı, kanama, dispepsi, kilo kaybı, bulantı ve kusma üst gastrointestinal sistem hastalıklarının sık görülen semptomlarındandır. Bu semptomlar, benign bir hastalığın belirtisi olabileceği gibi, malign bir duruma da işaret edebilirler. Bundan dolayı, bu semptomlara sahip olan hastaların olabildiğince erken, endoskopi ile değerlendirilmeleri gerekir (1-3). Biz bu çalışmamızda; endoskopi ünitemizde üst GIS endoskopisi uygulanan hastaların özofagus, mide, proksimal duodenum hastalıklarının sıklığını retrospektif olarak belirleyip sunmayı amaçladık.

Yücel Y, Aktümen A, Aydoğan T, et al. Upper gastrointestinal endoscopy: A retrospective analysis of 7703 cases. Endoscopy Gastrointestinal 2016;(24):1-3.
Background and Aims: This retrospective study aims to determine the incidence of diseases of the esophagus, stomach and proximal duodenum among patients who underwent upper gastrointestinal endoscopy in our endoscopy unit. Materials and Methods: The study uses the reports of endoscopies that were done in the endoscopy unit at Karabük University Training and Research Hospital from 2006 to 2012 to determine the ages, genders and incidence of diseases of the esophagus, stomach and proximal duodenum. Results: In this six-year period, endoscopic procedures were performed on 7703 patients, 4578 (59.4\%) of whom were female and 3125 (40.6\%) male, because of upper gastrointestinal complaints. The women ranged in age from 18 to 83 (mean: 57.8), while the men were aged 20 to 93 (mean: 54.3). The endoscopies found no pathology in 565 of the patients. Upper gastrointestinal endoscopy was performed with topical pharyngeal anesthesia on 99.2\% of the patients. Gastric cancer was found in 1.4\% of the patients who underwent upper gastrointestinal endoscopy. No complications or mortality resulted from the endoscopic procedures. Conclusion: Esophagogastroduodenoscopy is still the gold standard in the diagnosis of upper gastrointestinal diseases and can be easily applied with topical pharyngeal anesthesia.The mortality and complication rates for this diagnostic procedure are very low.

Key words: Endoscopy, gastrointestinal system, gastric cancer

\section{GEREC ve YÖNTEM}

Çalışmaya, Karabük Üniversitesi Eğitim ve Araştırma Hastanesi endoskopi ünitesinde 2006-2012 ylları arasında üst GIS endoskopisi yapılan ve endoskopi işlemleri video arşivleme sistemine kaydedilen 7703 hasta alındı. Hastalara endoskopi işlemi ile ilgili bilgi verildi. Endoskopiler 8 saat açlık sonrası, işlem öncesi topikal farenks aneztezisi (Xylocaine 10 mikrogr/doz) ile yapıldı. Işlemden çok korkan ve topikal farenks aneztezisi ile endoskopiyi tolere edemeyen olgularda ise midazolam 1-5 mg ile intravenöz sedasyon sağlandı. Hastaların yaşı, cinsiyeti ve endoskopi raporlarındaki özofagus, mide ve proksimal duodenum hastalıkları belirlendi. Makroskopik tanılar patoloji örnekleri ile teyit edilmeye çalışıldı. Kontrol ve tedavi amaçlı endoskopiler çalışmaya alınmadı.

Endoskopide Z çizgisi ile mideye geçildiği yer arasındaki mesafenin $5 \mathrm{~cm}$ 'den fazla olması hiatal herni olarak kabul edildi. Alt özofagial sfinkter yetmezliği ise endoskop midede iken 
retrofleksiyon yapılıp mide içindeki hava boşaltıldıktan sonra 15-20 saniye izlemin sonucunda kardiyanın gastroskopu iyi sarmaması ya da açık kalması olarak tanımlandı. Özofajit evrelemesi, Los Angeles sinıflamasina göre yapıldı (4). Barrett özofagus; normalde skuamoz epitel ile döşeli özofagus epitelinin, özellikle distal kısımlarda metastatik kolumnar epitele dönüşmesi olarak tanımlandı (5).

\section{BULGULAR}

Üst GIS şikayeti nedeniyle altı yıllık süreçte 7703 hastaya endoskopik işlem yapıldı. Hastaların 4578'i (\%59.4) kadın, 3125’i (\%40.6) erkekti. Kadınların yaş aralığı 18-83 (ortalama: 57.8), erkeklerin ise 20-93 (ortalama: 54.3) idi. 617 (\%8) olguda intravenöz midazolam ile sedasyon sağlandı.

\section{Tablo 1. Olgularin endoskopik verileri}

\begin{tabular}{|c|c|c|}
\hline Tanı & Sayı (N) & Yüzde (\%) \\
\hline Normal & 565 & 7,33 \\
\hline Özofajit & 441 & 5,72 \\
\hline Hiatal herni & 689 & 8,94 \\
\hline Paraözofageal herni & 5 & 0,06 \\
\hline $\begin{array}{l}\text { Alt özofagial sfinkter (AÖS) } \\
\text { yetmezliği }\end{array}$ & 1451 & 18,83 \\
\hline Özofagus ülseri & 6 & 0,08 \\
\hline Özofagus divertikülü & 5 & 0,06 \\
\hline Özofageal polip & 1 & 0,01 \\
\hline Akalazya & 5 & 0,06 \\
\hline Özofagus varisleri & 57 & 0,70 \\
\hline Heterotopik gastrik mukoza & 13 & 0,16 \\
\hline Barrett özofagus & 106 & 1,30 \\
\hline Özofagus kanseri & 5 & 0,06 \\
\hline Antral gastrit & 4394 & 57,04 \\
\hline Pangastrit & 788 & 10,22 \\
\hline Eroziv & 125 & 15,8 \\
\hline Alkalen & 157 & 19,9 \\
\hline Noduler & 83 & 10,6 \\
\hline Diffüz & 423 & 53,7 \\
\hline Gastrik ülser & 283 & 3,67 \\
\hline $\begin{array}{l}\text { Gecirilmis mide operasyonu } \\
\text { (Bilroth I/II) }\end{array}$ & 130 & 1,68 \\
\hline Gastrik polip & 74 & 0,96 \\
\hline Gastrik kanser & 108 & 1,40 \\
\hline Bulbutis & 749 & 9,72 \\
\hline Bulboduodenitis & 253 & 3,28 \\
\hline Duodenal ülser & 523 & 6,78 \\
\hline Duodenal divertikül & 25 & 0,32 \\
\hline Duodenal polip & 16 & 0,20 \\
\hline
\end{tabular}

Hastaların 565'inin endoskopisinde patoloji tespit edilmedi. Üst GIS endoskopisinde teşhis edilen mide kanserli olgu sayısl 108 (\%1.4) ve \%24'ü kadın idi. 3 olgu 50 yaş altında olup, olguların yaş aralığı 42-93 (ort: 68.38) yaş idi. Mide kanserli olguların \% 4.6'sı stromal tümör, \%0.9'u nörondokrin tümör, \%0.9'u lenfoma, \%93.6'sı ise adenokarsinoma idi.

Yapılan endoskopik işlemler sırasında herhangi bir komplikasyon gelişmedi ve mortalite görülmedi.

Endoskopide saptanan patolojiler Tablo l'de, patolojilerin organlara göre dağılımı Tablo 2'de, mide kanserlerinin lokalizasyonlarına göre dağılımı da Tablo 3'de özetlenmiştir.

\section{TARTIȘMA}

Üst GİS endoskopisi özofagus, mide ve proksimal duodenum hastalıklarının semptomlarını ortaya çıkarmada en güvenilir yöntemdir. Endoskop eski dönemlerde daha çok tanısal amaçlı kullanılmasına karşın terapötik endoskopların geliştirilmesiyle tedavi amaçlı kullanımı da yaygınlaşmaktadır. Üst GIS endoskopisi esnasında sedatif ve analjezik ajan kullanımı hastane ve ülkeye göre değişmektedir. Günümüzde bilinçli sedasyon yapan ajanların endoskopik işlemlerdeki gerekliliği konusunda fikir birliği yoktur. Avrupa, Güney Amerika ve Asya'da gastroskopi, sigmoidoskopi gibi nisbeten basit işlemlerde, genellikle sedasyon uygulanmamaktadır. Sedasyon, doğru tanı koymak, hasta ve hekim açısından konforu artırmak için faydalıdır. Ancak monitorizasyon ve işlem sonrası takip gerektirmesi nedeniyle, hasta müracaat oranının fazla olduğu endoskopi ünitelerinde işlem sayısını azaltabilir (68). Endoskopi ünitemizin şehrimizde tek olması ve ünitemize müracaat eden hasta sayısının fazla olması nedeniyle, olgula-

Tablo 2. Endoskopideki patolojilerin organlara göre dağılımı

\begin{tabular}{|lcc|}
\hline Organ & Sayı $(\mathrm{N})$ & Yüzde $(\%)$ \\
\hline Özofagus & 2784 & 27,50 \\
\hline Mide & 5777 & 57,04 \\
\hline Duodenum & 1566 & 15,46 \\
\hline Toplam & 10127 & 100 \\
\hline
\end{tabular}

Tablo 3. Mide kanseri vakalarının lokalizasyonlarına göre dağılımı

\begin{tabular}{|lcc|}
\hline Tanı & Sayı $(\mathbf{N})$ & Yüzde (\%) \\
\hline Proksimal mide & 33 & 30,6 \\
\hline Korpus & 41 & 37,9 \\
\hline Antrum & 33 & 30,6 \\
\hline Nüks & 1 & 0,9 \\
\hline Toplam & $\mathbf{1 0 8}$ & $\mathbf{1 , 4}$ \\
\hline
\end{tabular}


rın \%92'sine tek başına topikal farenks aneztezisi ile üst gastrointestinal sistem endoskopisi yapıldı.

Üst gastrointestinal sistem endoskopi sonuçları incelendiğinde patolojiler en fazla midede görülmekteydi (\%57.04). Mide patolojileri içinde de en fazla gastrit bulundu (\%89.70). Peptik ülser \%10.45 ve duodenal ülser/gastrik ülser oranı 1.84 bulundu. Gastrit ve peptik ülser oranları literatürle uyumluydu $(1,7)$.

Üst GIS endoskopisinin komplikasyonu çok nadirdir. Açlık süresi yeterli olmayan ya da mide boşalması geç olan hastalarda aspirasyon pnömonisi ortaya çıkabilir. Sedasyon sağlamak için verilen ilaca karşı reaksiyon ve verilen ilacın yan etkisi olabilir. Yabancı cisim çıkarılırken, duodenum ve mide poliplerine polipektomi yaparken perforasyon ve kanama görülebilir. Endoskopi işlemi sırasında kardiyak ve pulmoner hastalıkları olanlarda ölüme kadar giden tablolar ortaya çıkabilir. Çalışmamızda, endoskopi yapılan hastaların yaş ortalaması diğer çalışmalara kıyasla daha yüksekti ve buna rağmen komplikasyon, mortalite oranı \%0 bulundu (7, 9-11).

\section{KAYNAKLAR}

1. Loffeld R, Van der Putten A. The yield of UGIE: a study of a ten-year period in the 'Zaanstreek'. Neth J Med 2003;61:14-8.

2. Tamer A, Korkut E, Korkmaz U. Üst gastrointestinal endoskopi sonuçlar1: Düzce bölgesi. The Medical Journal of Kocatepe 2005;6:31-4.

3. Nur N, Yılmaz A, Yıldız G. Gatrointestinal sistem kanamalı hastaların özellikleri, endoskopi ve biyopsi sonuçlarının değerlendirilmesi. CÜ Tıp Fakültesi Dergisi 2007;29:42-6.

4. Lundell LR, Dent J, Bennett JR, et al. Endoscopic assesment of esophagitis: Clinical and functional correlation and further validation of the Los Angeles classification. Gut 1999; 45: 172-80.

5. Calvet X, Villoria A. Esophageal diseases: gastroesophageal reflux disease and Barrett's esophagus. Gastroenterol Hepatol 2012;35:26-34.

6. Aydogan H, Aydogan T, Uyanikoglu A, et al. Propofol-ketamine combination has shorter recovery times with similar hemodynamics compared to propofol alone in upper gastrointestinal endoscopy in adults. A randomized trial. Acta Medica Mediterranea 2013;29:77.

7. Uyanıkoğlu A, Davutoğlu C, Danalıŏlu A. Peptik ülser ve kanser teşhisinde özofagogastroduodenoskopi [Esophagogastroduodenoscopy for peptic ulcer and cancer]. Akademik Gastroenteroloji Dergisi 2011;10:108-11.

8. Oğuz D, Köksal AS, Çiçek B, et al. Tanısal amaçlı endoskopik ultrasonografi yapılan hastalarda bilinçli sedasyon: Midazolam ile plaseboyu karşılaştıran randomize, çift kör, kontrollü çalışma. Akademik Gastroenteroloji Dergisi 2005;4:100-5.
Üst GIS endoskopisi mide kanseri riskinin yüksek olduğu bölgelerde tarama amaçlı da yapılabilir. Mide kanserinde bölgeler arasında ciddi farklılıklar ortaya çıkabilmektedir. Ailesinde mide kanseri hikayesi olan hastalara mide kanseri risk yüksekliğinden dolayı endoskopi yapılabilir. Mide kanseri erkeklerde kadınlardan iki kat daha fazla görülür. Genellikle 40 yaşından sonra ortaya çıkar ve yetmişli yaşlarda pik yapar. Her zaman belirti vermeyebilir. Mide kanserinin en sık görüldüğü lokalizasyon antrumdur ve literatürde mide kanseri oranı \%0.5-4 arasında değişmektedir (2, 12-14). Çalışmamızda Karabük bölgesinde hastanemize üst gastrointestinal şikayet nedeniyle müracaat ederek üst GIS endoskopisi uygulanan olgularda mide kanseri oranı \% 1.4 olup literatürle uyumluydu. Erkek/kadın oranı 3.15, en fazla görüldüğü lokalizasyon korpus ve hastaların yaş ortalaması ise 68.38 idi (Tablo 3).

Üst GIS endoskopisi; topikal farenks anestezisi ile kolaylıkla yapılabilen, mortalite-morbidite oranı oldukça düşük olan ve üst gastrointestinal sistem hastalıkların teşhisinde altın standart olarak kabul edilen bir teşhis yöntemidir.

9. Sarıoğlu M, Kaçam G, Bektaşi M, et al. Son iki dekatta endoskopi merkezinde özofajit görülme siklığında saptanan değişiklik. Endoscopy 2009;17:1-5.

10. Ateş M, Köşüş A, Köşüş N, Güler A. Results of upper gastrointestinal system endoscopy in women with dyspeptic symptoms. Eurasian J Med 2009;41:80-3.

11. Nazlıgül Y, Uslusoy H, Yılmaz N, et al. Şanlıurfa yöresinde üst gastrointestinal endoskopi bulguları ve Helicobacter pylori pozitifliği. Van Tıp Dergisi 1999;6:1-3.

12. Dursun M, Yılmaz Ş, Canoruç F, et al. Mide karsinomlarında anatomik lokalizasyon. Dicle Tip Dergisi 2002;29:1-2.

13. Tuncer I, Uygan I, Kösem M, et al. Van ve çevresinde görülen üst gastrointestinal sistem kanserlerinin demografik ve histopatolojik özellikleri. Van Tip Dergisi 2001;8:10-3.

14. Uyanıkoğlu A, Coşkun M, Binici DN, et al. Erzurum yöresi gastroskopi ve patoloji sonuçlarının değerlendirilmesi [Evaluation of gastroscopic and pathologic results Erzurum region]. Türkiye Klinikleri J Gastroenterohepatol 2011;18:70-4 